\title{
Applying Lexical Rules Under Subsumption
}

\author{
Erhard W. Hinrichs \\ Dept. of Linguistics \\ University of Tübingen \\ Wilhelmstr. 113 \\ D-72074 Tübingen \\ Germany \\ eh@sfs.nphil .uni-tuebingen de
}

\author{
Tsuneko Nakazawa \\ NTT' Laboratorics \\ 1-2356 Take, Yokosuka 238-03 \\ Japan \\ tsunekoonttnly.ntt.jp
}

\begin{abstract}
Lexical rules are used in constraintbased grammar formalisms such as Head-Driven Phrase Structure Grammar (IIPSG) (Pollard and Sag 1994) to express generalizations among lexical ontries. 'This paper discusses a number of lexical rules from recent IIPSG analyses of German (Hinrichs and Nakazawa 1994) and shows that the grammar in some cases vastly ovcrgenerates and in other cases introduces massive spurious structural ambiguity, if lexical rules apply under unification. Such problems of overgeneration or spurious ambiguity do not arise, if a lexical rule applies to a given lexical entry iff the lexical entry is subsumed by the left-hand side of the lexical rule. Finally, the paper discusses computational consequences of applying lexical rules under subsumption.
\end{abstract}

\section{Introduction}

Current linguistic theories place an increasing amount of grammatical information in the lexicon and employ a variety of mechanisms to express generalizations across lexical entries: templates (Flickinger 1987, Shieber 1986), inheritance hierarchies (Flickinger 1987, Pollard and Sag 1994), and lexical rules (Bresnan 1982, Dowty 1982, Gazdar et al. 1985, Pollard and Sag 1994). Lexical rules (henceforth: LRs) have been subjected to particularly close scrutiny. 'This rescarch has focused on two important issues: 1. how the use of IRs affects the generative power of grammar formalisms and the computational complexity of parsing algorithms (Uszkoreit and Peters 1986, Carpenter 1991), and 2. how to provide a denotational semantics for LRs (Calcagno and Pollard 1995, Meurers 1995). In this paper we address neither of these two issues. Instead we will concentrate on a question that we consider to be of equal importance, but that has reccived surprisingly litile attention: Under what conditions should an $\mathrm{I} R$ be applicable to a given lexical cntry (henceforth: L,F)? For grammar formalisms that employ the notion of unification of attribute-value structures, two criteria for applicability naturally suggest themselves:

1. Hypolhesis $A: \Lambda$ lexical rule applies to a lexical cntry iff the lexical entry unifes with the left-hand side of the lexical rule.

2. IIypothesis $B: \Lambda$ lexical rule applies to a lcxical cutry iff the lexical entry is subsumed by the left-hand side of the lexical rule. ${ }^{1}$

Without much argument, it is commonly assumed that Ilypothesis A is correct (cf. Pollard and Sag 1994, Calcagno and Pollard 1995, and Meurers 1995). 'This paper argues that ITypothosis $\Lambda$ should be rejected on empirical grounds. We discuss a number of IRs that have beon used in IIPSG analyses of German (Hinrichs and Nakazawa 1994) and show that the grammar will eithor vastly overgencrate and accept ungrammatical sentences or introduce spurious structural ambiguity for grammatical sentences, if Hypothesis A is adopted. However, no such problems of overgencration or spurious ambiguity arise, if one adopts Iypothesis B, instead.

It would go beyond the scope of this paper to present a fully worked-out proposal on how to process LRs in a computational system for IIPSG. However, as discussed in section 6 , it is worth noting that the subsumption test for LR application can be integrated straightforwardly into two recent proposals by van Noord and Bouma (1994) and by Meurers and Minnen (1995) of how to imploment LiRs in a processing system for HPSG.

\footnotetext{
${ }^{1}$. This paper will not provide a formal definition of subsumption or unificiation for typed feature structures. Instead, we refer the reader to the standard definitions of Kasper and Rounds (1986) and Carpenter (1992), among many others. Informally speaking, two feature structures are unifiable iff they do not contain incompatible information. One feature structure subsumes another iff the information contained in the former is less specific than in the latter.
} 


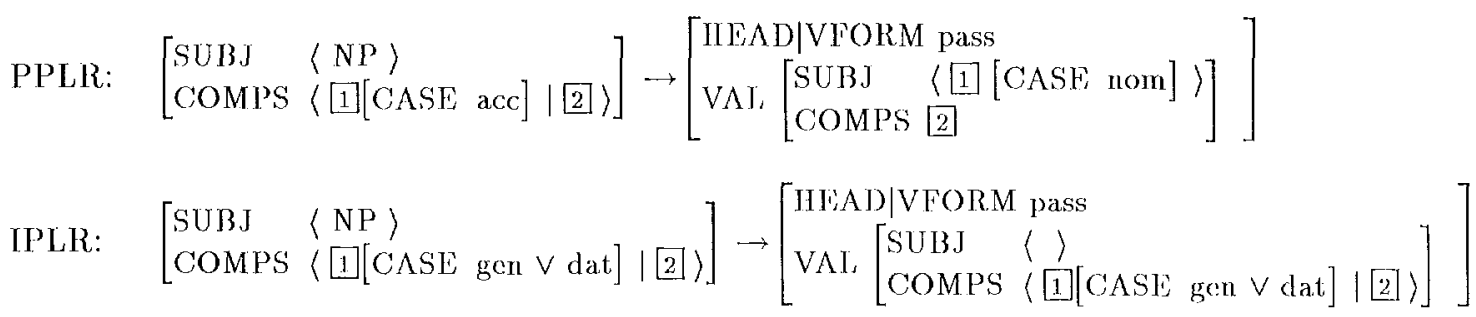

Figure 1: Passive Lexical Rules for German -- Kiss 1992

\section{Passive by Lexical Rule}

It has been assumed in a variety of syntactic frameworks that the active/passive alternation should be treated as a lexical process: Bresnan (1982) in LFG, Dowty (1982) in Categorial Guammar, and Pollard and Sag (1987) for HPSG. German exhibits two types of passives: personal passives, as in (1b), and impersonal passives, as in $(2 \mathrm{~b}, 3 \mathrm{~b})$.

(1) a. Peter sah den Mann.

'Peter saw the man.'

b. Der Mann wurde gesehen.

'The man was seen.'

(2) a. Poter half dem Mann.

'Peter helped the man.'

b. Dem Mann wurde geholfen.

'The man was helped.'

(3) a. Dic Veteranen gedachten der Toten.

'The veterans commernorated the dead.'

b. Der 'Toten wurde gedacht.

"The dead were commernorated.'

For personal passives the accusative object NP of a transitive verb, e.g. den Mann in (1a), in its active form corresponds to an NP' with nominative case, e.g. der Mann in (1b). In impersonal passives a dative or genitive NP complement of a transitive verb, e.g. the dative NP dem Mann in (2), exhibits the same case assignment in the active and passive forms. 'Io formally capture the relationship between the Jis for active and passive forms of German verbs in IIPSG, Kiss (1992) formulates the I.Rs in Fig. 1 (henceforth referred to as the PPIR and the IPLR, respectively). ${ }^{2}$

'The LRs in ling. 1 employ the HPSG feature geometry of Pollard and Sag (1.994). ${ }^{3}$ The specification of a syntactic category (CAI') in $\mathrm{HIPSG}$

\footnotetext{
${ }^{2}$ However, sce Kathol (1994) and Pollard (1994) for an account of German passive without LRs.

${ }^{3}$ In order to reduce the size of the feature structures, prefixes of paths that bogin with the SYNSEM attribute have been omitted as much as possible in Fig. 1 and all other feature structures that are shown in this paper.

According to Kiss, specifying two different case values under one recntrancy (cf. tags [1] in the PPLR) is a shorthand notation for identity of the two categories in all respects, except for the case value. 'The original
}

includes the feature VAIENCF (abbreviated as VAL in Fig. 1), which in turn specifies for verbs under the features SUIBJ and COMPS the subject and non-subject complements. COMPS takes a list of categories, called synsem objects, as its value. If the list is non-empty, the leftmost category in the list reprosents the direct object. The intended effect of the PPLIR is to promote the direct object of a transitive verb in the LE for the active form to the subject of the passive form. For impersonal passives the COMPS list of any transitive verb whose leftmost complement is marked by genitive or dative case remains unchanged, while the singleton list of the subject value of the active form becomes the empty list in the LE for the passive form. Note that the case specifications on the left-hand side of the rules are crucial since they condition which classes of transitive verbs apjear in personal and impersonal passives.

Viewed procedurally, the PPIR is meant to ap ply to LAs for transitive verbs such as kaufen as shown in Fig. 2. ${ }^{4}$ lor transitive verbs it makes no difference whether we use mification or subsumption as the test of applicability for the PPIR. 'The Lit for any transitive verb is more specific than the feature structure of the input description of the PPIR, since the PHON value and the COMPS and SUBJ values will be further instan tiated than in the input description of the PPLE. In particular, the COMPS list of the PPLR is entirely schematic for any non-empty list of categories whose first element is an accusative NP while the COMPS valuc for kaufen is a list with cxactly one element that has the same category and case specification as the NP in the Pl'LR. 'Therefore, the LJ' will both unify with and bo subsumed by the input feature structure of the PPLR. However, as we will see in the next section, the choice of subsumption or unification makes a crucial difference when Lis are thenselves highly schematic and underspecified.

formulation of the LRs by Kiss (1992) differs from the version presented here in minor definitional details. However, these differences are entirely orthogonal to the theorctical issues discussed in this paper.

${ }^{4}$ Following abbreviatory conventions in HPSG, the subscripted tags in Fig. 2 stand for the index values contained in the CONTENT specifications of the NPs. 


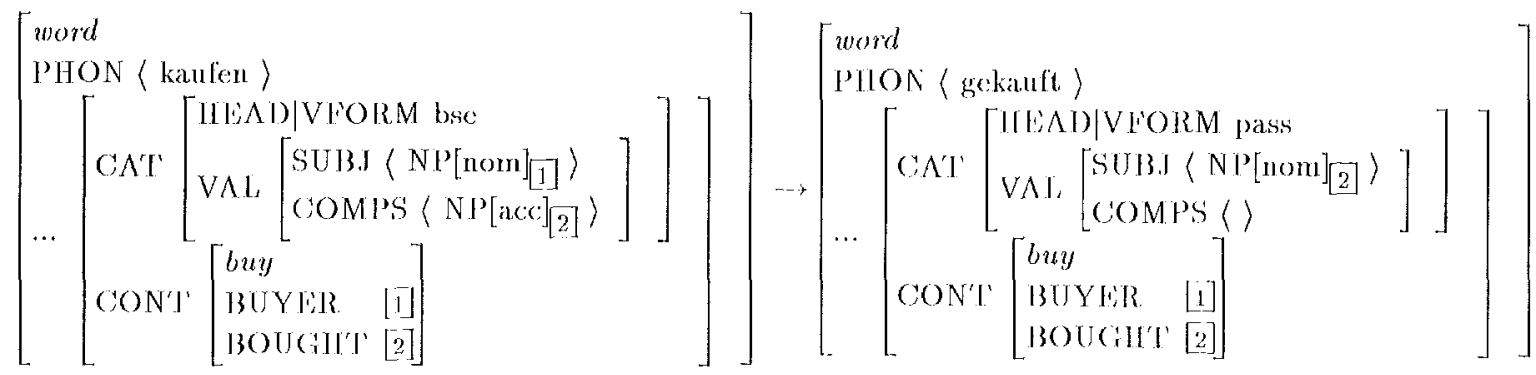

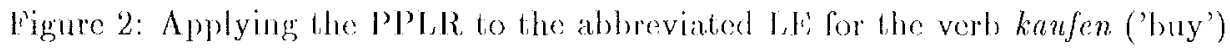

\section{Argument Composition in the Lexicon}

'The notion of argument composition was first introduced into the TIPS( and Nakazawa (1989) to account for the topicalization of verbal constituentis and for the anxiliary flip construction in German. ${ }^{5}$

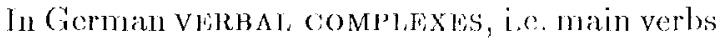
togetber with non-finite anxiliaries, such as lesen können can be topjealized, as shown in (1).

(4) Jesen können wird or es.

read can will hejt,

'He will be able read it.'

In addition, the verbal complex serves as the do main over which anxiliaries can be fronted. This so-called AUXmanry will construction positions finite anxiliaries such as wird in (5) to the lofi. in the verbal complex, instoad of the customaty sentence-tinal position for subordinate clauses.

(5) Ich glaube nicht, dab er es wird lesen können.

I believe not thathe it will read can

'I don't believe that he will be able to read it.'

Topicalization and auxiliary-flip, thus, provide crucial ovidence for treating main verbs and auxiliaries as constituents. 'I'he proposed constituent structure requires that subcalegorinalion information about non-verbal complements is propagated from the main verb to the top of the verbal complex. In IIPSG this ean be achicved by structure sharing the complenents of the main verb with the subcalegorization information of each auxiliary in the sentence. 'Th is leads to the for atmiliaries such

\footnotetext{
"IIPSC practicioners have adopted the notion of argument composition to account for a variety of syntactic: constructions in tifferent languages, incheding clitic-climbing in ltalian (Monaxhesi 1993), the syntactic properties of auxilaries in French ( $A$ beillé and Godard 1994), and cross-serial dependencies in Jutch (Rentier 1994).
}

as können 'Can' shown in Pig. 3.

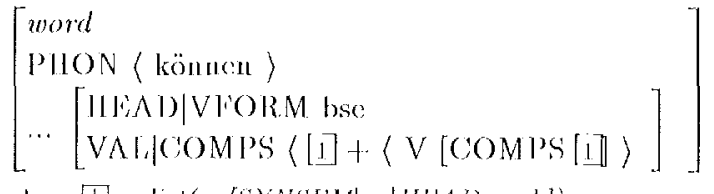

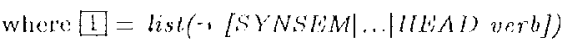

l'igure 3: Abbreviated f, for anxiliary könuen

können requires a base infinitive complement, as indicated in the COMPS value in tig. 3. The (OMPS value of können also contains a (possibly (enp)ty) list of non-verbal categories (identified by the tag 1) that the governed verb subcaticgorizes for." In other words, the COMPS value of the governed vorb is merged with the (OMPS list of können itself. Formally this merging is achieved by ippending the (OOMPS list of the governed verl with the one-element list that consists of t.he governed verb itself. Since anxiliaries have ho be able to combine: with different types of verlos (c.g. intransitives, transitives, diturasitives, cte.), the COMPS list of the governed verl has to remain underspecified. It is this moderspecilication in the I, for anxiliaries thationases a crucial difference in the applicability of JRs.

\section{Subsumption and Unification Revisited}

For interactions between the L Wis for anxiliaries such as konnen and the passive IR For Greman, it makes a crucial difference whether the IR applies under unification or uuder subsumption. First. consider mification as the test for applicability of ThRs. Since the lis for können does not contain any information that is inconsistent with the in. put specilication of the PPTR in Jig. L, the rule is applicable and will produce the derived $\mathrm{L}$, for

\footnotetext{
${ }^{6}$ Hor further details as to why the list of raised ele ments has to be restricted to contain only non-verbal categories see Hinrichs and Nakazawa (1994).
} 
können in Fig. 4.

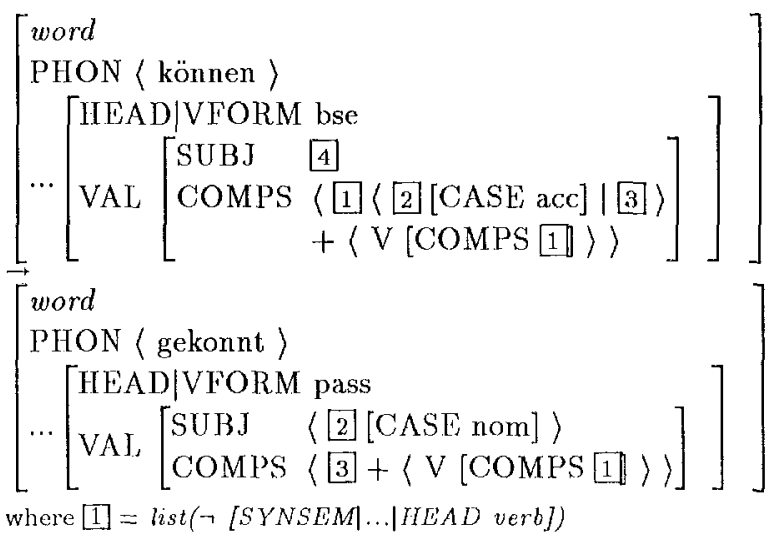

Figure 4: Applying the PPLR to können under unification

When the LE for können is unified with the lefthand side of the PPLR, the COMPS list of können - and, via structure sharing, the COMPS value of the governed verb - becomes further instantiated. This COMPS list now contains as its leftmost element a category with accusative case. In accordance with the PPLR, this leftmost element is promoted to the SUBJ value of konnen, while the remainder of the COMPS list of the verb governed by können, identified by tag 3 , is retained. However, this derived $\mathrm{L} \mathrm{E}$, would have the undesirable consequence that it admits ill-formed sentences such as (6).

(6) * Das Auto wurde kaufen gekonnt. the car was bought can

In (6) the auxiliary können has been passivized and the direct object of the transitive verb has been promoted as the subject of können. However, since in German only main verbs can be passivized, the sentence is ungrammatical. ${ }^{7}$

Ungrammatical sentences such as (6) can be successfully ruled out if the PPIR is applied to an $\mathrm{L} E$ only if the input specification of the LR subsumes the LE (Hypothesis B). The subsumption requirement for $L R$ application is based on the insight that LRs should apply only to LEs that are instantiated at least to the extent that the input description of the LR minimally requires. In the case at hand, the list of raised arguments in the I.E for können in Fig. 3 is totally unspecified - it can be any list of non-verbal synsem objects, including the empty list. The COMPS list of the left-hand side of the PPLR, on the other hand, requires the leftmost element to carry accusative

\footnotetext{
${ }^{7 T}$ There are some cases of "long distance" passives, i.e. passives which involve the complement of an embedded verb, that at least some German speakcrs accept, e.g. Der Hund wurde vergessen zu füttern ('It was forgotten to feed the $\operatorname{dog}^{\prime}$ ): However, we are not aware of any German speakers that would allow passives with raising verbs such as können.
}

case. Therefore the COMPS list of konnen does not subsume the COMPS list on the left-hand side of the PPLR, or vice versa. Accordingly, no subsumption relationship exists between the input specification of the PPIR as a whole and the LE for können. Hence if Hypothesis B is assumed, the LR can be successfully blocked. ${ }^{8}$ However, even under subsumption nothing blocks the PPLR from applying to the transitive verb kaufen, as discussed in section 2. Therefore the grammatical sentence in (7) can be derived successfully.

(7) Das $\Lambda$ uto wurde gekauft.

'The car was bought.'

\section{Avoiding Spurious Ambiguity}

This section will consider the interaction of highly schematic LEs with another LR commonly used in HPSG: the Complement Extraction LR, formulated for English by Pollard and Sag (1994). Fig. 5 shows the version of the Complement Fxtraction Lexical Rule for German (henceforth: CELRG) that has been proposed by Hinrichs and Nakazawa (1994)

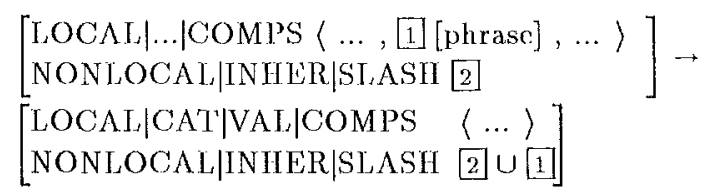

Figure 5: Complement Extraction Lexical Rule for German - Hinrichs and Nakazawa 1994

The CELRG moves an element from the COMPS list of a verb to its SIASH set. The value of the feature SL $\Lambda$ SH contains those items that are realized in left dislocated position, e.g. as a topicalized constituent in sentence-initial position. Analogous to the applicability of the PPLR, the CELRG is applicable to LEs of transitive verbs such as kaufen shown in Fig. 2, under both unification and subsumption. The result of such an application is the same as shown in Fig. 2, except that the direct object is placed on the SLASH set instcad of the SUBJ list. For the analysis of sen-

\footnotetext{
${ }^{8}$ The reader may wonder whether one couldn't get around the requirement that the LR for passive apply under subsumption by restricting the rule to apply only to main verbs. At first glance this seems like a possible way-out, since the cases that we have considered problematic for applying the LR under unification involve $\mathrm{J}, \mathrm{Es}$ of auxiliaries. ITowever, the class of argument raising verbs is not restricted to auxiliaries. Verbs such as verstehen ('know how'), as in L'r versteht Parser zu implementieren ('He knows how to implement parsers.'), fall into the same class. But verstehen is a main verb, not an auxiliary. Thus, even if the LR would be reformulated to apply 'only to auxiliaries, the following ungrammatical sentence could not be excluded: * Parser werden verstanden zu implementieren.
} 


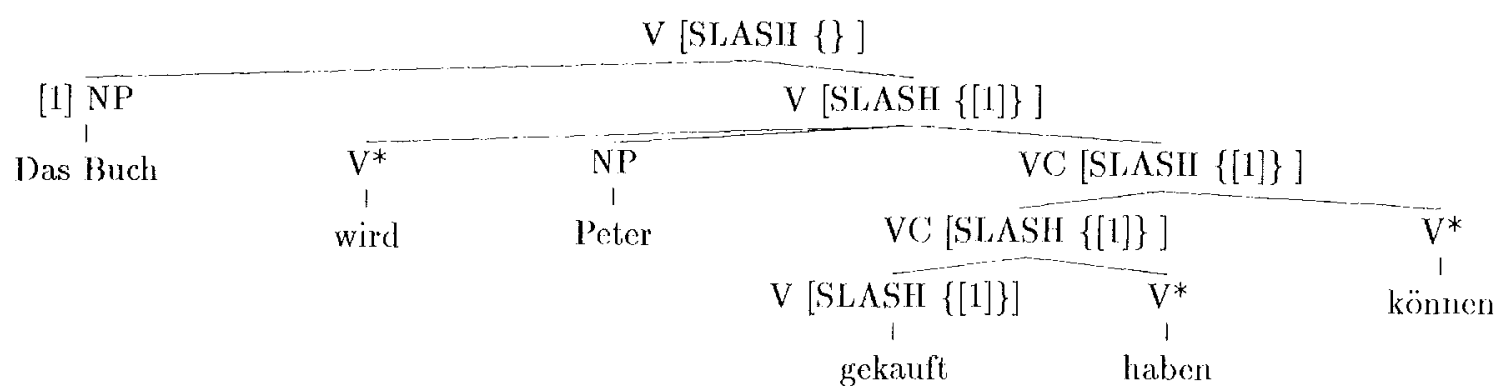

Vigure 6: Analysis 'Iree for Sentence (8)

tence (8), the tree in Fig. 6 illustrates the percolation of the relcvant SL $\Lambda$ SH value that is introduced via the CELRG in the LE for kaufen. ${ }^{9}$

(8) Das Buch wird Peter gekauft haben können. the book will Peter bought have can 'Peter will have been able to buy the book.'

The ShASII value in Fig. 6 is percolated from the non-terminal node for the verb kaufen by the Nonlocal leature P'rinciple to the sister node of the topicalized constituent das Buch. The top local trce is licensed by the Hcarl-liller II) Schema which binds off the SL $\Lambda$ SH value so that the sentence node has an empty SI ASII set. ${ }^{10}$

The CELRG restricts topicalized constituents to phrasal categories. This restriction is necessary to rule out sentences such as (9) in which a single lexical item, i.e. a word in terms of the type hierarchy of HPSG, is topicalized.

(9) * Können wird Peter das $\Lambda$ uto gekauft haben can will Peter the car bought have

$\Lambda s$ in the case of the PPLR, the difference between Hypotheses $A$ and $B$ comes into play when we consider the interaction of the CLIRG with highly schematic entries such as the ones Ilinrichs and Nakazawa (1994) assume for auxiliaries in German. If Hypothesis $\Lambda$ is assumed, then the CELRG will be applicable to the type of LI's shown for können in Fig. 3, since such an IS will muify with the input description of the LR. One of the possible outputs of the LR, to such an auxiliary cntry would look identical to the putative output of the PPLR shown in lig. 4, expect that one of the clements from the COMPS list of the auxiliary is assigned to the SLASH set instead of the SUBJ list. However, this would have the undesirable consequence that the SLASII value in

\footnotetext{
${ }^{9}$ The tree in Fig. 6 assumes the flat constituent structure for German clanse structure proposed by Hinrichs and Nakazawa (1991). However, the issue raised with respect to the CFIRG in this paper is orthogonal to overall assumptions of German clause structure.

${ }^{10}$ See Pollard and Sag (1994) and Himrichs and Nakazawa (1994) for further details on the Nonlocal Feature Principle and the Head-filler ID Schema.
}

the analysis of topicalized sentences that contain auxiliaries conld originate in the I, $\mathrm{E}$ for the main verb, but also in the LF for each auxiliary present in the sentence. Hence, in addition to the tree in Fig. 6 , three additional trees are admitted for sentence (8) in which the SLASII value originates in one of the pre-terminal nodes for the anxiliaries. These nodes are rnarked for emphasis by an asterisk in Fig. 6. This ambiguity is, of course, totally spurious since it does not correlate with a difference in semantics or any other relevant linguistic, property of the sentence. lrom a computational perspective, such spurious ambiguities are highly undesirable since they force the parser into considering multiple analyses where a single analysis suffices. 'I'he spurious ambiguity that we have just iclentified is particularly pernicious, since it would affect a wide range of sentences in any grammar of German that employs argument composition and the CELRG: all assertion main clauses that contain auxiliaries would be affected since in assertion clauses the initial constitucnt is the result of topicalization.

Once again undesirable consequences of overapplying an LR under unification can be avoided if applicability of LRs instead requires subsumption (Iypothesis B). Since the CHLRG limits extracted constituents to phrases and since the COMPS list of an auxiliary does not restrict its dements in the same way, the IS for anxiliaries and the input description of the CEIRG do not stand in a subsumption relation. Hence under Пуpothesis 13 the CNIRG applies only to main verls, and the tree in Fig. 6 is the only tree admittod.

\section{Computational Consequences}

Finally, we will consider the computational implications that the adoption of Hypothesis 13 has for the processing of LRs in a computational system. Since consensus on how to provide an adequate: denotational semantics for LRs has not yet been reached, it would go well beyond the scope of this paper to dcvelop a fully worked-out proposal on how to process IRs. ${ }^{11} \Lambda$ very promising approach

\footnotetext{
${ }^{11}$ See Calcagno and Pollard (1995) and Meurers (1995) for further discussion.
} 
on how to integrate LRs into processing systems for HPSG has been developed independently by van Noord and Bouma (1994) and by Meurers and Minnen (1995). It turns out that the conclusions reached in this paper can be easily integrated in the gencral framework that these authors provide.

Common to these two proposals is the idea of treating LRs as (Horn clause) constraints on LFs of the kind shown schematically in Fig. 7.

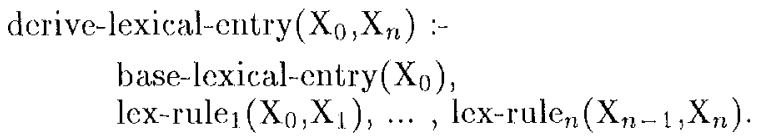

ligure 7: Iexical rules as Horn. Clause constraints on relations between lexical entries

Definite clause schemata as in Fig. 7 (for $n \succeq$ 0 ) define relations between base LFs listed in the lexicon and derived Ll's that are obtained via the application of a sequence of I,Rs. Each I,R is then viewed as a two-place definite relation as illustrated in Fig. 8 for the PPILR of Fig. 1.

$$
\begin{aligned}
& \text { lex-rule }\left(\left[\begin{array}{ll}
\text { SUBJ } & \langle\text { NP }\rangle \\
\text { COMPS } & \langle 1[\text { CASF acc }]|[2]
\end{array}\right],\right. \\
& \left.\left[\begin{array}{l}
\text { HFAl)|VFORM pass } \\
\text { VAJ, }\left[\begin{array}{ll}
\text { SUJJ } & \langle 1][\text { CASE nom }]\rangle \\
\text { COMPS } 2
\end{array}\right.
\end{array}\right]\right)
\end{aligned}
$$

Figure 8: The PPIR cncoded as a definite relation

It is important to distinguish two tasks that need to be performed in computing with lexical rules: ${ }^{12}$

1. the algorithm that decides for a given lexical cntry whether a lexical rule is applicable to it, and

2. the algorithrn that computes for a given lexical entry the output specification of the lexical rule, i.e. the derived lexical entry.

The subsumption test for lexical rule application that we have argued for in this paper pertains to the first task. 'The execution of the definite clauses of the kind shown schematically in Fig. 7 , which encode the possible relations between base and derived lexical entries, pertains to the second task.

Regarding the first task, in van Noord and Bouma's approach the sequences of lexical rules that are applicable to a given base lexical entry have to be spccified by the grammar developer along with delay statements, which allow goal freezing at run time of not sufficiently instantiated relations. In Meurers and Minnen's approach such sequences are automatically generated from

\footnotetext{
${ }^{12}$ This distinction is rightly emphasized by Calcagno and Pollard (1995).
}

the set of base lexical cntries and the set of lexical rules specified by the grammar. The allowable sequences of lexical rules are compiled into finite state automata which are in turn cncoded as definite clause attachments to baso lexical entries.

Note that both approaches are general enough to accommodate different assumptions about the applicability of lexical rules to lexical entries, i.e. they are compatible with both Hypotheses $\Lambda$ and 13 . Whether or not a given lexical rule applies to a lexical entry in van Noord and I3ouma's approach needs to be stipulated by the grammar writer who is in theory free to use either a unification or subsumption test. In Menrers and Minnen's approach the deduction rules for automatically generating a finite-state encoding of lexical rules can likewise be based on a subsumption check or a unification check. In this paper wo have argued on empirical grounds that subsumption should be the relevant operative criterion. The theoretical results of the present paper can therefore be straightforwardly integrated into a lexical rule cornpiler of the sort described by Meurers and Minnen in which applicability of lexical rules is checked automatically under subsumption.

\section{Conclusion}

This paper has discussed a number of lexical rules from recent IIPSG analyses of Gcrman (Hinrichs and Nakazawa 1991) and has shown that the grammar in some cases vastly overgenerates and in other casos introduces massive spurious structural ambiguity, if lexical rules apply under unification. ${ }^{13}$ flowever, no such problems of overgeneration or spurious ambiguity arise, if a lexical rule applies to a given lexical entry iff the lexical entry is subsumed by the left-hand side of the lexical sule. Finally we have shown that the subsumption test for the applicability of lexical rules can be integrated straightforwardly into the proposals by van Noord and Bouma (1991) and by Meurers and Minnen (1995) of how to implement lexical rules in a processing system for $1 \mathrm{PSG}$.

\footnotetext{
${ }^{13} \mathrm{It}$ is worth pointing out that the importance of subsumption has been noted for other linguistic phenomena as well. Building proposals originating with Gazdar et al. (1985), Baycr and Johnson (1995) have pointed out that the grammar of (cross-categorial) coordination for Linglish will make the right predictions if the mother category of the conjunction schema is required to subsume the category of each conjunct. By contrast, if the relation between the mother category and each daughter category is that of unifiability, then the resulting grammar vastly overgenerates.
} 


\section{References}

Anno Abeille and Daniele Godard. 1994. 'T'he Complementation of l'rench Auxiliaries. Proceedings of the Thirleenth West Coast Conference on Formal linguistics. CSLI Publications/SLA, Stanford Universily.

Sam Bayer and Mark Johnson. 1995). Peahures and Agroment. Proccedings of the $39 \mathrm{rd}$ Annual Mecting of the Association of Compulational Linguistics. MI'l', Cambriclge, Mass.

Joan Bresinan. 1982. Passive. Bresnan, J. ed. The Mental Representation of Crammatical Relations, Cambridge, MA: 'The MI'L' Press.

Michael Calcagno and Car! Pollard. 1995. Jexical Rules in IIPSG: What are they. Proceedings of the ACQUll RX II Workshop on Lexical Rules. Cambridge, UK.

Bob Carpenter. 1991. 'The Generative P'ower of Categorial Gummars and Moad-Driven Phrase Structure Commons with lexical Rules. Computational Linguistics. Vol. 17.3, Pp. 301-311.

Bob Carpenter. 1992. The logic of Typed lieature Structures. Cambridge Tracts in Theoretical Computer Science. Cambridge University Press.

David R. Dowty. 1982. Grammatical rolations and Montague grammar. Jacobson, P. and (A. K. Pullum eds. The Nature of Synlactic Representation Dordrecht: 1). Reidel.

Dan Flickingor. 1987. Lexical Rules in the 11 crarchical leabon. Ph.D. Lhesis, Stanford Uni. versiby, Stauford, (, $\Lambda$.

Gerald Gazdar, liwan Klein, Geofrey Pullum and Ivan Sag. 1985. Cencralized Phrase Struchure Grammar. Oxford: Basil Blackwell.

Erhard W. Hintichs and 'lsuneko Nakazawa. 1989. Subcategorization and VP' Structure in German. Paper presented at the Third Symposium on Germanic Linguistics, Purdue University: Lalfayette, Indiana. Published in L:. Hinrichs and 'I'. Nakazawa. A spects of Cerman VI' Structure. STS Techucal Report 01-93, Dept. of Timguistics: University of 'T'ïbingen.

Hrlarel W. Ilinrichs and 'T'suncko Nakazawa. 1994. Partial VP' and Split-NP' 'Topicalization in German. An IITSG Analysis. F. Hinrichs, D. Meurers and 'I'. Nakikiawa eds. Arbeilsberichle acs Sonderforschungsbercichs 340. Stutigart, and 'I'übingen, pp. 1-46.

Robert Kasper and William Rounds. 1986. A Logical Semantics for Feature Structures. Procecedings of the gath Annual Mceling of the Association of Computational linguistics. Now York, N.Y.
Andreas Kathol. 1994. Passives Without lexical Rules. In Nerboune et al. eds. Cerman in lleadDriven Phrase Structure Grammar. CSII I.ecture Notes No. 46, University of Chicago P'ress and CSLI, Chicago.

Paul John King. 1989. A logical formalism for head-driven phrase structure grammar, Ph.J). thesis, University of Manchester.

'I'ibor Kiss. 1992. Variable Subkategorisicerumg line 'Theore der unpersönlichen Konstruktio non in Deutschen. Linguistische Berichte Vol. 140, pp. $250 \cdot 293$.

W. Dedmar Mcurers. 1995. Towards a Semantics for Iexical Rules as Used in HPSG. Procedings of the $A C Q$ UThliX II Workshop on lexical Rules. Cambridge, UK.

W. Detmar Meurers and Guido Minnen. 1995. A Computational 'Treatment of AIPSC Lexical Rules as Govatriation in Lexical Fintries. Prococdings of the lifin International Workshop on Nalural linguage Vnderstanding and Logie Programming. Lisbon, Portugal.

Paola Monachesi. 1993. Object Clitics and Clitic Glimbing in thaliatu IIPSC: Gammats. Proccedings of the Sixth Confcrence of the lituropean Chapler of the Assocation of Compulational linguistics. Utrecht, 'The Nethorlands.

Carl Pollard. 1994. 'Loward a Unificd Aceount of Passive in German. In Nerbome et al eds. Ger man in Head-Driven Phrase Siructure Crammar. CSild lacture Notos No. 46, University of Chicago Press and (SSLI, Chicago.

Carl Pollard ind lvan Sag. 1987. InformationBased Syntax and Semantics: Volume I - liundamentals (STI Lecture Noles, Volune 13. Stanford: Center for the Study of I auguage and Information.

Carl Pollard and Ivan A. Sag. 1994. Ilead-1)riven Phrase Structure Grammar. Chicago: University of Chicago P'ress and Stanford: CSLI Pub. lications.

Gerrict M. Rontier. 1994. A I,exicalist Approach to Dutch Cross-Serial Dependencies. Papors from the 30th Regional Meeting of the Chicago Linguistices Society. (thicago, Illinois.

Stuart Shicber. $1986 . \quad A n$ Introtuction to Unificalion-based Aprotaches to Grammar Csial lecture Notes No. 1. Chicago: Juiversity of Chicago Press and Stanford: CS'Stel Publications.

Jlans Uszkoreit and Stanley Peters. 1986. On some Formal Properties of Metarules. linguistics and Philosophy Vol. 9.4, pp. 177-494.

Gertjan van Noord and Gosse Bouma. 1994. The Scope of $\Lambda$ djuncts and the Processing of laxical Rules. Procedings of COLING $9 / 4$ Kyoto, Japall. 